\title{
Creating a Publication Platform for High-Quality Negative Results
}

\author{
Elliot S. Gershon ${ }^{1 *}$, Xiaogang Chen ${ }^{2}$ \\ ${ }^{1}$ Department of Psychiatry and Behavioral Neuroscience, University of \\ Chicago, 5841 S. Maryland Ave. MC 3077, Chicago, IL 60637, USA; \\ ${ }^{2}$ Mental Health Institute, Central South University, Changsha 410011, Hunan \\ Province, China.
}

*Corresponding Author: Elliot S. Gershon. Email: egershon@yoda. bsd.uchicago.edu.

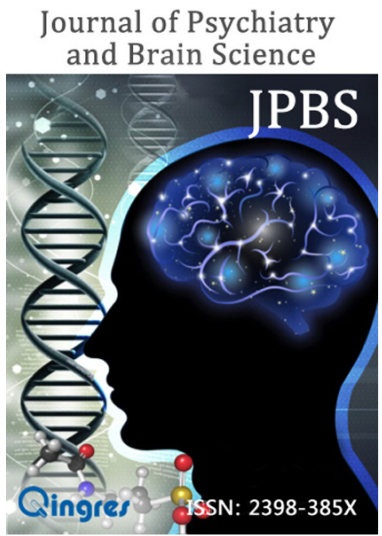

https://jpbs.qingres.com

GOPEN ACCESS

DOI: $10.20900 / j p b s .20180008$

Received: August 15, 2018

Accepted: August 24, 2018

Published: August 24, 2018

Copyright: $\odot 2018$ by the authors, Licensee Qingres, London, United Kingdom. This is an open access article distributed under the terms and conditions of the Creative Commons Attribution License (CC BY 4.0, https://creativecommons.org/licenses/by/4.0/).
The importance of negative results from well-designed experiments is widely recognized in science. This is particularly true in human studies, where there have been repeated issues of non-replication of statistically significant results, as reviewed and analyzed by John P.A. loannidis ${ }^{[1]}$. A paper on "Top 10 Replicated Findings from Behavioral Genetics" by Robert Plomin et al. ${ }^{[2]}$ is a useful example of how difficult it can be to assemble all the negative results on important topics in behavior and related neurobiology.

The Journal of Psychiatry and Brain Science (JPBS) has decided to contribute to the problems of replicability in our areas of interest, by publishing papers with critically designed experiments, high quality execution and analysis, and negative results. Clinical trials in psychiatry and neurology, genetic analyses, neurobiological studies, and animal models of psychiatric disorders, would be areas of particular interest. We will also publish meta-analyses related to reproducibility issues, and articles on experimental design and analysis related to reproducibility.

The negative reports should follow this structure:

Introduction: Define the purpose of the negative report and its significance. Relevant literature should be reviewed and controversial findings should be cited.

\section{Materials and Methods}

This section should describe in detail how the study was conducted, including:

- Subjects

- Study Design

- Experimental Procedures

- Data Analysis: Graphical and Tabular Displays for Analysis 


\section{Results}

Discussion: A perspective on the results presented, including statistical power of this study and of the known other studies.

Elliot S. Gershon

Xiaogang Chen

Editors-in-Chief

\section{REFERENCES}

1. Ioannidis JP. Non-replication and inconsistency in the genome-wide association setting. Hum Hered. 2007; 64(4): 203-213.

2. Plomin R, DeFries JC, Knopik VS, Neiderhiser JM. Top 10 Replicated Findings From Behavioral Genetics. Perspect Psychol Sci. 2016; 11(1): 3-23. 